\title{
HEADACHES, SLEEP AND ACADEMIC SUCCESS
}

IN ADOLESCENTS

sonoescolas@gmail.com

Teresa Rebelo-Pinto (1)

Joana Carneiro-Pinto (2)

Helena Rebelo-Pinto $(1,2)$

Teresa Paiva $(1,3)$

(1) CENC, Lisbon Sleep Medicine Center

(2) Lisbon Catholic University - Psychology Department

(3) Faculty of Medicine - Lisbon University

\section{MATHERIALS \& METHODS}

We used a specific questionnaire that included:

- Cleveland Adolescent Sleepiness Scale

(CASQ)

- Sleep related habits

- Sleep complaints

- Health complaints

- Demographics (including academic grades)

Teachers from 31 schools across Portugal collected data from $7^{\text {th }}$ to $12^{\text {th }}$ grades, between January and April 2012.

We used SPSS to analyse data.

\section{$<$ Sleep Duration on weekdays} $(p=0.008)$

$>$ Sleep Duration on weekends $(p=0.045)$

$>$ Daytime Sleepiness

\section{CONCLUSIONS}

These results suggest that in adolescents headaches are also related to sleep deprivation or sleep problems. In the future, we should pay more attention to headaches as a symptom of sleep problems and explore which factors may mediate the risk of academic failure in the presence of headaches. Furthermore, the high level of headaches in younger people across all age groups supports the need of early intervention.

\section{INTRODUCTION \& OBJECTIVES}

Sleep complaints often correlate with other health and social problems. During a national study about sleep habits in adolescents, we observed a very high frequency of headaches, so the aim of this work was to analyse what could be correlated with this complaint in terms of sleep duration, daytime sleepiness, academic success, age and gender.

\section{RESULTS}

$$
\mathrm{N}=6838
$$

12 - 22 years old

Mean age $=14.97(1.99)$

$53.3 \%$ females

$53.8 \%$ (3671) reported having headaches regularly

$$
(p=0.000)
$$

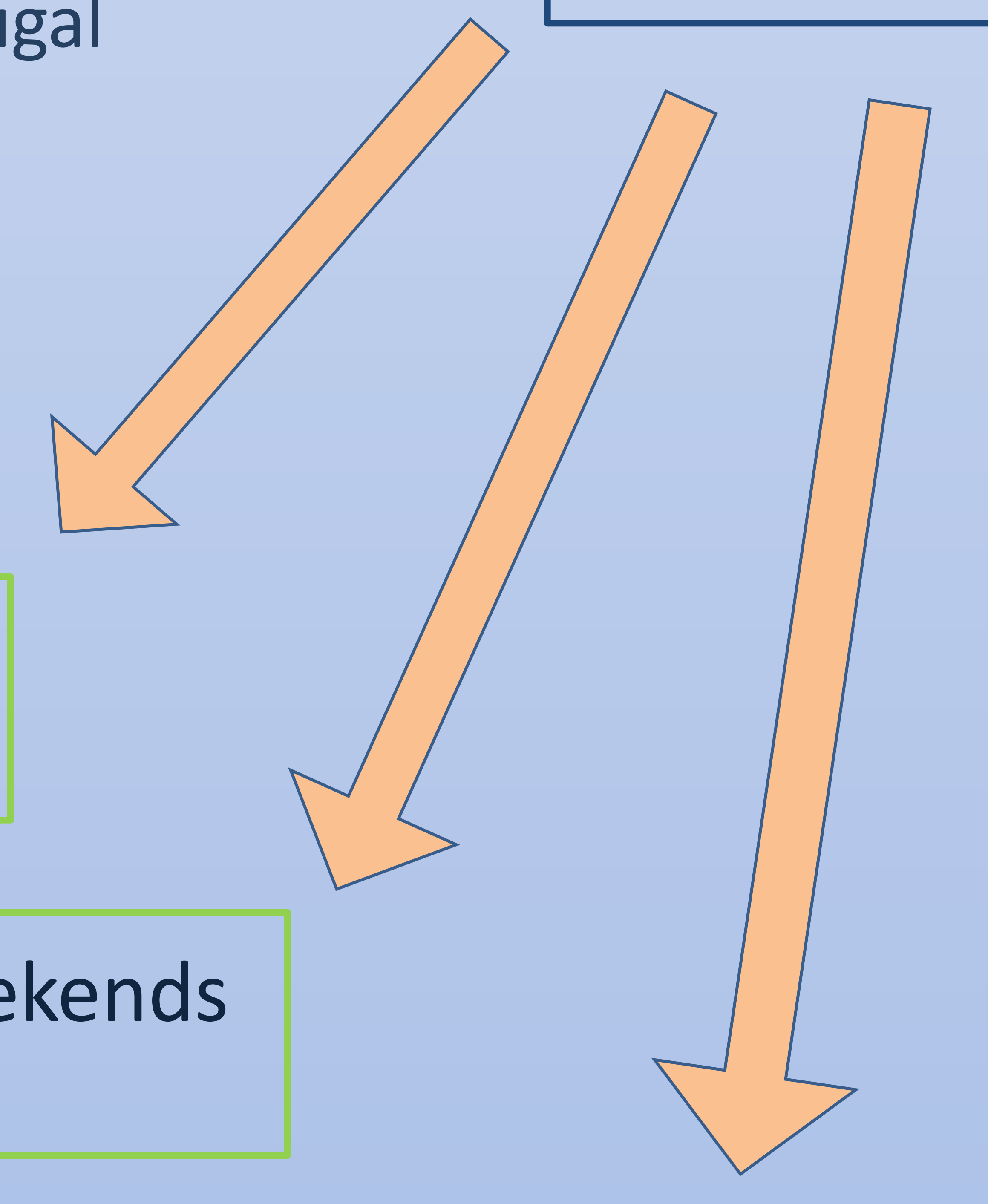
$(p=0.000)$

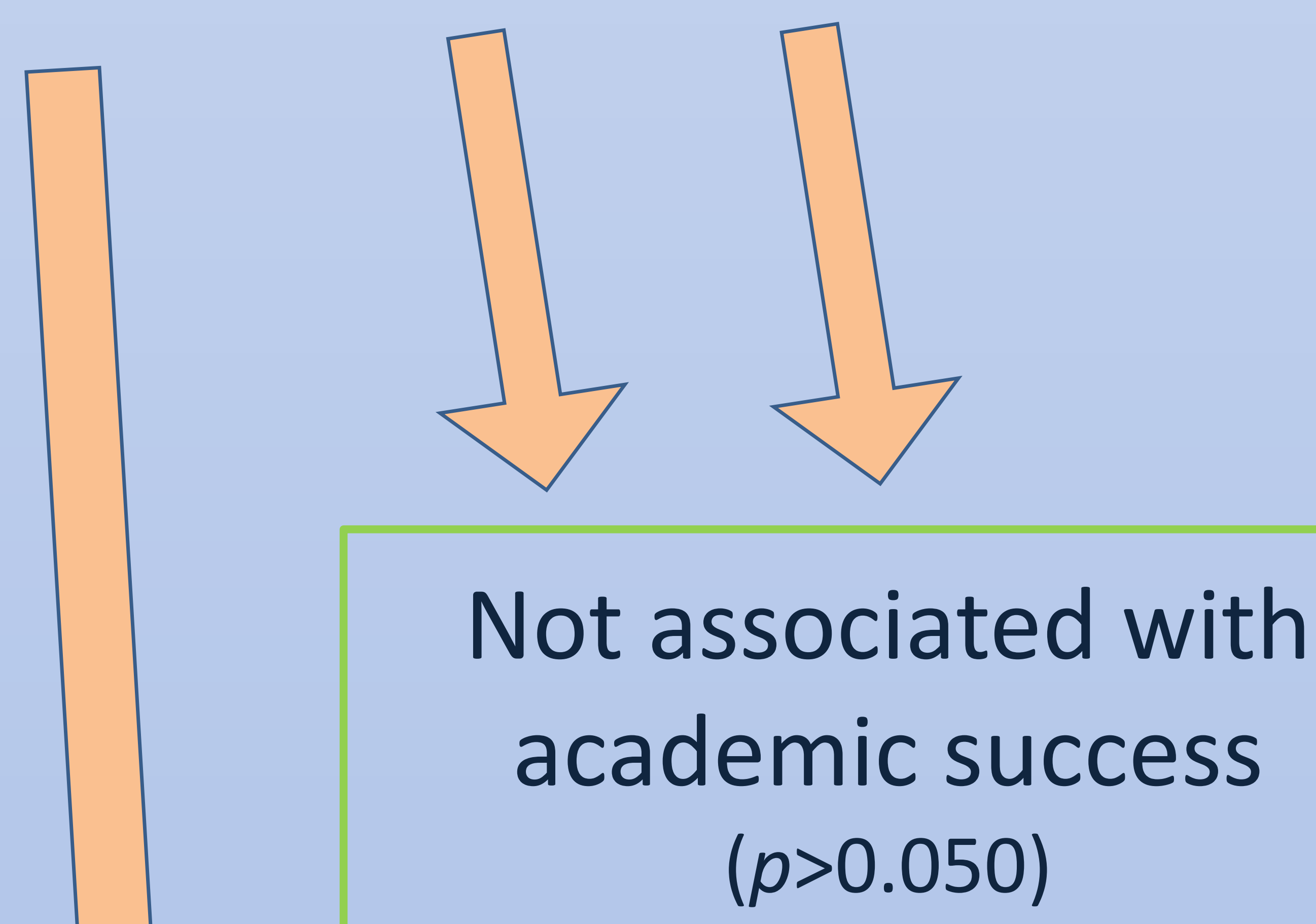

No differences between age groups $(p=0.098)$ 